\title{
RELAÇÓES FAMILIARES E MIGRAÇÃO: UM MODELO TEÓRICO-CLÍNICO EM PSICOLOGIA ${ }^{1}$
}

\author{
FAMILY RELATIONS AND MIGRATION: A CLINICO- \\ THEORETICAL MODEL IN PSYCHOLOGY \\ RELACIONES FAMILIARES Y MIGRACIÓN: UN \\ MODELO TEÓRICO-CLÍNICO EN PSICOLOGÍA
}

Ivy Daure*

Odile Reyverand-Coulon**

Sabine Forzan***

\section{Resumo}

Este artigo propóe um modelo teórico-clínico na abordagem terapêutica às famílias de imigrantes de primeira geração e seus descendentes. A primeira fonte de dados, a pesquisa de Doutorado realizada na Universidade de Bordeaux entre 2005 e 2006, foi desenvolvida com nove famílias de imigrantes na França, de origem brasileira, italiana e portuguesa, seguindo os critérios de inclusão: imigração do casal de mesma origem em idade adulta e nascimento dos filhos no país de adoção. A segunda fonte, a atividade clínica em psicologia, serviu de espaço de observação e de aplicação do modelo proposto. Conclui-se que a transmissão cultural e familiar favorece o duplo pertencimento e constitui elemento significativo na integraçáo dos imigrantes e seus descendentes, bem como para a imagem de si e nas relaçóes familiares. Os suportes social e governamental desempenham papel importante ao valorizarem a diferença cultural. A proposta original é a terapia familiar com base no modelo sistêmico e na psicologia intercultural, em que a história da imigração e seu impacto nas relaçóes intra e extrafamiliares mostram-se, pela integraçáo das perspectivas cultural e migratória, mais próximas da realidade daquele sujeito em dificuldades psicológicas e sociais que demanda ajuda nos serviços de psicologia e de psiquiatria.

\footnotetext{
* Universidade de Bordeaux, Bordeaux, França.

** Universidade de Bordeaux - 2, Bordeaux, França.

*** Hospital Charles Perrens, Bordeaux, França.
} 
Palavras-chave: relações familiares; migração; transmissão cultural e familiar.

\section{Abstract}

This paper propose a clinic-theoretical model for the study of first-generation immigrant families and their descendants. Data came from two sources. The first was the research investigation conducted with nine immigrant families of Brazilian, Italian, and Portuguese origin in France, subject to the following inclusion criteria: couples of the same origin, who immigrated in adult life and birthed children in the host country. The second data source was clinical psychology activity, which served as a space for observation and application of the proposed model. Cultural and familial transmission favors "double belonging" and constitutes a significant element of integration among immigrants and their descendants, as well as an element of self-image and family relations. Social and governmental support valuing cultural differences plays an important role in such dynamic. Original proposal for family therapy based on a systemic model of intercultural psychology, in which history of immigration and its impact on intra- and extra-familial relations demonstrate, by the integration of cultural and migratory perspectives, to be closer to the reality of the subject in psychological and social (psychosocial) difficulties seeking psychological and psychiatric services.

Keywords: family relations; migration; cultural and familial transmission.

\section{ReSUMEN}

Este artículo propone un modelo teórico-clínico en la abordage terapéutica en las familias de inmigrantes de primera generación y sus descendientes. La primera fuente de datos, utilizada en la investigación de Doctorado realizada en la Universidad de Bordeaux entre los ańos 2005 a 2006, fue trabajada con nueve familias que inmigraron a Francia, siendo sus orígenes brasileros, italianos y portugueses, fueron considerados los siguientes criterios de inclusión: inmigración de la pareja del mismo origen en edad adulta y nacimiento de los hijos en el país de adopción. La segunda fuente fue la actividad clínica en psicología que sirvió de campo de observación y de aplicación del modelo propuesto. Se concluyó que la transmisión cultural y familiar favorece su doble participación y constituye un elemento importante en la integración de los inmigrantes y sus descendientes, en relación con su propia imagen y en sus relaciones con su familia. Los apoyos social 
y gubernamental juegan un papel importante al valorizar la diferencia cultural. La propuesta original y la terapia familiar basada en un modelo sistémico y en la psicología intercultural en que la historia de la inmigración y su impacto en las relaciones intra e extra familiares se manifiesta por la integración de las perspectivas cultural e migratoria más próxima de la realidad de aquel sujeto en dificultades psicológicas y sociales, que demanda ayuda de los servicios de psicología y de psiquiatría.

Palabras clave: relaciones familiares; migración; transmisión cultural e familiar.

\section{Introduçáo}

Este trabalho se apoia no modelo sistêmico de compreensão do sujeito, tomando em conta o sistema do qual faz parte e no qual evolui, ou seja, a família, a escola, a sociedade e o país. Do ponto de vista social, a questão da imigração na Europa - e, em particular, na França - exige do Estado uma postura reflexiva e adaptativa através dos serviços sanitários, educativos e sociais.

Sem dúvida, a sociedade francesa é, cada vez mais, multicultural. Neste sentido, os profissionais de saúde vêm sendo mais solicitados por famílias de origem estrangeira. Evidentemente, o universo da psicologia não é exceção, o que é constatado por Mousset (2011).

$\mathrm{Na}$ tentativa de compreensão desse fenômeno e do impacto psicológico e relacional da imigração na dinâmica familiar, confrontamo-nos com escassa literatura sobre o tema no âmbito da teoria sistêmica. Em face de tal dificuldade, orientamo-nos no sentido da psicologia intercultural, modelo que se inscreve em uma tradição psicanalítica e que se preocupa com a questão da pluralidade cultural e da "solução" de interseção dessas particularidades do ponto de vista social e psíquico do sujeito individualmente.

A leitura sistêmica tem os seus artefatos clínicos, como, por exemplo, o genograma, a anamnese familiar, a atitude do terapeuta e a noção do contexto. Do nosso ponto de vista, a psicologia sistêmica seria um modelo teórico que poderia abarcar a particularidade da condição do imigrante e compreender o sujeito no contexto familiar, estando mais próxima da realidade das interaçóes intra e extrafamiliares tão importantes no processo de integração sociocultural. Nessa perspectiva, a análise do movimento migratório do ponto de vista psicológico e a tentativa de interseção entre o modelo sistêmico e o intercultural se impóem (Morrone e Mereu, 2003). 
A migração é quase sempre a expressão de um desejo de satisfação pessoal através do projeto de ascensão social. Para tanto, o sujeito parte de um mundo onde os códigos sociais e linguísticos são previsíveis para aterrissar em um universo no qual tudo é desconhecido. Os sentimentos de incompreensão e de incompetência estão frequentemente associados à aventura migratória, e a constatação de diferença talvez seja a coisa mais dolorosa para o imigrante (Reveyrand-Coulon, 2011).

Guerraoui (2001) comenta que a ruptura imposta pela imigração significa uma fragilização das referências habituais do sujeito, pois tudo o que era evidência em sua vida quotidiana, deixa de ser.

Grinberge e Grinberg (1986) ensinam que a imigração é processo desenvolvido em três etapas, as quais são, ao mesmo tempo, bem definidas cronologicamente, embora se influenciem mutuamente:

- A primeira, a decisão de partir, é acompanhada do anúncio do projeto de imigração e das pessoas que se associam ou não a essa decisão, definindo a atmosfera emocional em torno dessa viagem.

- A segunda, a viagem, em termos de deslocamento, de passagem entre dois mundos, e as apreensóes, descobertas e encontros que este processo comporta.

- A terceira etapa é a da chegada ao país que se tornará o de adoção, marcada pelo sentimento de acolhimento, ou não, por parte dos nativos, pelos primeiros momentos da vida no país estrangeiro e pelas eventuais dificuldades encontradas.

Certamente que a maneira como o imigrante vive o processo imigratório em termos das três etapas descritas por Grinberg e Grinberg (1986) influencia a sua atitude tanto em face à sociedade de acolhimento quanto com relação ao seu país de origem.

Para nós, as primeiras impressões sobre a imigração são marcantes na história do sujeito, que faz referência a elas em cada momento de crise da sua vida. Aqui entendemos "crise" no sentido sistêmico, como descreve Ausloos (2001), ou seja, todo momento que conduz um sistema - por exemplo, uma família - à mudança. A crise pode ser vivida como positiva ou negativa pelos membros do sistema, mas tem a evolução do sistema como função principal. Essa referência se torna ainda mais forte quando se trata de traumatismo, pois a lembrança traumática é ativada em todos os momentos delicados, como, por exemplo, o nascimento dos filhos em terra estrangeira. 
Estamos de acordo com Vasquez (1993) quando descreve o comportamento do imigrante e o de seus descendentes em forma de balança, ou seja, o sujeito deve aprender a compor com as duas culturas durante o processo de transculturação. Do nosso ponto de vista, a "composição entre as duas culturas" pode corresponder a uma maneira de viver o duplo pertencimento. Nesse sentido, dependendo de ser o prato da balança mais pesado do lado de uma cultura ou de outra e da maneira como o peso das representaçóes, dos valores e das regras intrafamiliares se exprimem, um impacto direto se exerce sobre as relaçóes familiares, no lugar de cada um no sistema, nas expectativas da família etc. $\mathrm{O}$ evento migratório se torna, de certo modo, organizador das relaçóes intra e extrafamiliares como fenômeno que influencia a evolução de uma família em várias geraçôes e que contribui à construção do mito familiar.

No entanto, a abordagem sistêmica vem se interessando de maneira discreta, somente nos últimos anos, pela questão da família imigrante, o que nos parece paradoxal quando se sabe que nas relaçôes familiares a comunicação entre os membros de uma família e o contexto de evolução de um sistema são das principais unidades de análise do terapeuta sistêmico (Daure, 2006). Um dos elementos para a compreensão desse paradoxo pode ser encontrado na teoria de Friedman (1994) sobre o sistema, que influenciou fortemente o pensamento sistêmico, na qual se defende que as famílias têm, entre elas, mais similitudes do que diferenças, ao passo que as variáveis, como raça, gênero e etnia, não são muito significativas para as famílias, tal como não o são para a terapia. Para esse pesquisador, todas as famílias são acessíveis e inteligíveis por meio do mesmo modelo teórico.

Outro aspecto que poderia contribuir para a banalização do impacto da imigração no íntimo das famílias estaria na dificuldade do terapeuta em negociar com uma cultura diferente da sua, uma vez que esse exercício requer a postura de aceitaçáo no que se refere ao desconhecimento do profissional no tocante à outra cultura, ao mesmo tempo que demanda o reconhecimento da competência do paciente, o qual pode exprimi-la acerca da própria cultura.

Por conseguinte, quando o terapeuta ignora a importância do duplo pertencimento cultural na vida do sujeito e de sua família, ele inibe de maneira involuntária qualquer expressão da cultura dominada. É interessante registrar que Andolfi (2004) comenta a noção de cultura dominante para definir a cultura do país de acolhimento onde vivem os imigrantes e a de cultura dominada, como referência à cultura de origem. Esta última denominação expressa um sentimento de opressão descrito por alguns imigrantes. No sentido do acolhimento do sujeito em terapia, Mugnier (1998) aborda o ponto importante, que é o "pensable du thérapeute", ou seja, os elementos que fazem parte do universo mental do tera- 
peuta, o que ele é capaz de imaginar, os aspectos aos quais faz referências em suas análises, que viabilizam a criação de um espaço de confiança e a possibilidade de expressão da condição de vida do imigrante, dessa aparição em seu discurso: do que era a sua vida antes da imigração, da família que ficou no país de origem, das tradiçóes que gostaria de transmitir aos seus descendentes, enfim, da maneira como cada um exprime o seu duplo pertencimento cultural (Daure, 2011). Assim, uma leitura sistêmica da história imigratória, bem como as repercussões nas famílias que demandam terapia, não pode passar em silêncio, mesmo se sabemos que, na maioria dos casos, como descrevem Grinberg e Grinberg (1986), a geração que imigra raramente solicita ajuda psicológica, gênero de dificuldade expressa pelos descendentes de segunda e terceira geração. Para estes, a imigração dos pais ou dos avós está distante e, por essa razão, não associam que as dificuldades vividas por eles podem estar ligadas a essa parte da história da família. São raras as consultas em psicologia nas quais o sujeito descreve os seus sintomas como tendo origem na imigração de outro membro da família.

Não se trata, para nós, de determinismo em termos da psicopatologia do imigrante e de seus descendentes, mas da tentativa de trazer a questão da imigração para a cena da terapia. A falta de formação dos psicólogos e dos trabalhadores sociais com relação à psicopatologia do imigrante, adicionada à escassez de políticas públicas destinadas a favorecer o acolhimento do imigrante e seus descendentes seguem o sentido de uma lógica assimilacionista, pela qual o imigrante deve fazer tábula rasa do seu passado cultural para melhor incorporar a cultura do país de imigração. Semelhante contexto paralisa a reflexão sobre o imigrante e torna aleatório o trabalho do profissional em função de sua eventual sensibilidade.

Sabemos que temas delicados, como a diferença e a alteridade, podem provocar, com frequência, atitudes opostas no nativo: ou de rejeição ou de fascinação. Nos dois posicionamentos, o afeto toma espaço muito importante, e podemos deduzir que a construção teórica se torna fundamental como suporte de reflexão do profissional/nativo que trabalha com uma população de imigrantes. Nosso artigo se inscreve também nessa perspectiva de suporte reflexivo.

\section{Metodologia}

\section{Hipótese de trabalho}

O evento imigratório provoca certo desequilíbrio no sistema familiar. Este desequilíbrio implica uma reorganização, a qual depende da capacidade de esta- 
belecer relação entre a cultura de origem e a cultura do país de acolhimento, o que se pode traduzir na apropriação, por parte dos filhos, da história da imigração dos pais e das referências das duas culturas.

\section{População}

Quatro famílias brasileiras, três famílias italianas e duas famílias portuguesas fizeram parte deste estudo. A escolha de trabalhar com famílias de origens diversas se justifica pelo desejo de construção de um modelo aplicável a famílias em situação multicultural, independentemente das culturas. Por sua vez, estas três nacionalidades são consideradas, na França, populaçóes que apresentam poucos problemas do ponto de vista da integração e, em razão disso, poucos trabalhos lhes são dedicados. Outro elemento que contribuiu para essa escolha foi o fato de as famílias poderem se exprimir na língua do país de origem ou na língua do país de acolhimento. Além deste, um critério de inclusão foi os pais serem da mesma nacionalidade e terem imigrado em idade adulta, bem como os filhos que participam da pesquisa serem nascidos na França.

Essas famílias foram contatadas através de associaçóes culturais ou por intermédio de uma rede informal de conhecidos. Nenhuma estava em terapia durante a pesquisa nem tinha o projeto de iniciar terapia.

\section{Procedimento}

Realizamos entrevistas semiestruturadas com cada membro da família individualmente e, três meses depois, efetuamos uma entrevista familiar. Nas entrevistas, exploramos os três tempos da imigração, segundo a proposta de Grinberg e Grinberg (1986), além da questão da transmissão cultural entre pais e filhos.

Solicitamos a cada participante que contasse a história da imigração - a sua ou a dos pais, de acordo com o interlocutor - enquanto as questóes do pesquisador serviam somente de suporte do discurso. Construímos um genograma de cada família, fundamentando-nos nos dados coletados com cada membro da família, o qual foi validado no momento da entrevista familiar. Registramos todos os encontros com a ajuda de gravador e os transcrevemos em seguida.

\section{Unidades de análise}

Para a investigação da questão da transmissão cultural, utilizamos quatro indicadores do quotidiano: a língua, a culinária, a música - tomamos em conta a 
literatura, a dança e a música, ou seja, as expressóes culturais - e as relaçóes com a família que vive no país de origem. O nível de conhecimento dos filhos a respeito da cultura dos pais permitiu-nos avaliar a capacidade de circulação da informação da família e de inferirmos a utilização das duas culturas no quotidiano das famílias.

\section{Procedimento de análise}

Realizamos uma análise qualitativa de cada entrevista, além da análise comparativa tanto entre famílias de mesma origem quanto de origens diferentes. A utilização do programa Tropes, que propóe uma análise quantitativa do discurso, complementou a análise qualitativa, garantindo certa neutralidade.

\section{Resultados}

Através do estudo dessas famílias, podemos ressaltar que seis fatores aparecem como indispensáveis para que a transmissão cultural entre pais e filhos seja capaz de valorizar a utilização do duplo pertencimento cultural como vantagem na vida cotidiana e para que o imigrante possa construir uma boa imagem de si mesmo. Essa observação é confirmada na clínica do imigrante e sua família, o que nossa experiência testemunha (Daure, 2010).

Evidentemente, a fim de destacar esses seis fatores que potencializam a transmissão cultural, foi-nos preciso isolar, de maneira artificial, as questóes do traumatismo e do sofrimento provocados pela imigração, cujas influências se exercem sobre cada pessoa de maneira única. Poderíamos definir os três primeiros elementos como relacionados ao imigrante exclusivamente, enquanto os três últimos estariam ligados mais precisamente à relação entre o imigrante e seus descendentes no processo de transmissão cultural e familiar. São eles:

\section{Motivaçôes da imigração}

Cada imigração é única; no entanto, podemos observar certos tipos de imigração nos quais o ponto de vista do desejo do sujeito é bastante diverso. As imigraçóes por razóes econômicas ou políticas podem dar ao sujeito o sentimento de não ter escolha, pois o exílio seria a única maneira de melhorar sua qualidade de vida e, em casos mais extremos, o único modo de sobreviver. Não podemos fazer a mesma afirmação no que se refere às imigraçóes temporárias, isto é, aquelas por razóes de estudos, de trabalho ou sentimentais, que se tornam definitivas com 
o tempo, uma vez que nessas situaçóes o sujeito se sente relativamente livre para fazer a sua escolha. Foi-nos possível observar que esse sentimento de liberdade está relacionado, em certa medida, às disponibilidades psicológicas de curiosidade e de abertura do sujeito em direção ao país de acolhimento.

\section{Recepção do pais de acolhimento}

As primeiras impressóes que o imigrante tem no que concerne ao país de acolhimento podem ser facilmente descritas por ele várias décadas depois, como foi possível constatar neste trabalho de pesquisa e confirmar com nossa experiência clínica. $\mathrm{Na}$ situação em que se encontra o imigrante quando chega pela primeira vez no país de acolhimento, onde nada é familiar, a perda das referências, como, por exemplo, a língua, os espaços, os odores e os sabores, é acompanhada de um sentimento de insegurança em que tudo representa "um sinal". A amabilidade das primeiras pessoas que ele encontra se torna um sinal de aceitação. Se o dia está ensolarado, é um sinal de que tudo vai ficar bem, enfim... Essas associaçóes, que podem parecer anedóticas, são descritas por todas as pessoas que encontramos, sem exceção, como elementos de desconforto ou de estresse em suas relaçóes com o país de acolhimento e seus habitantes.

\section{Peso das representaçóes culturais}

Nós pudemos observar a importância do país de origem do imigrante em sua aceitação no acolhimento por parte dos habitantes universitários. $\mathrm{O}$ imigrante pode ser visto de maneira negativa devido a sua origem, como, por exemplo, entre um imigrante brasileiro e um imigrante português, o primeiro se sente mais bem acolhido que o segundo, mesmo nos casos em que os motivos das imigraçóes fossem idênticos: estudos universitários. $\mathrm{O}$ sentimento de acolhimento e de aceitação é evidentemente indispensável para que o imigrante possa afirmar o seu pertencimento cultural e vivê-lo como valor a colocar em evidência na relação social e no encontro com o outro. Ao contrário, a rejeição e o sentimento de exclusão podem levar o imigrante a um sentimento de insegurança sobre as suas competências culturais e a uma desvalorização de suas origens em detrimento da cultura do país de acolhimento.

\section{Possibilidade de se exprimir na lingua de origem}

Esse ponto relaciona-se diretamente ao precedente. $\mathrm{O}$ reconhecimento, o sentimento de segurança na sua cultura autoriza o imigrante a utilizar sua língua 
em certas ocasióes do cotidiano. No momento do nascimento dos filhos em situação de imigração falar a língua de origem se torna elemento importante no processo de transmissão, mas, para isto, os pais imigrantes devem ter a segurança quanto a essa transmissão ser positiva e que aportará uma competência suplementar para seus filhos, competência reconhecida como positiva pelo país de acolhimento.

\section{Apoio do grupo de compatriotas no país de imigraçâo}

No processo de transmissão, o contato com o grupo de compatriotas não deve ser compreendido como organizaçáo em gueto ou exclusiva, mas como a participação de pessoas de mesma origem cultural no cotidiano como ponto de referência em termos de compartilhamento. $\mathrm{O}$ exercício da parentalidade é baseado em apoio do grupo social; não é diferente em situação de imigração. Para o imigrante e seus filhos, o fato de observar e de participar de encontros com famílias de mesma origem cultural e de origem cultural diferente - como é o caso das famílias do país de acolhimento - pode ser um aspecto de reforço identitário significativo na evolução em direçẫo da organizaçăo familiar multicultural. Os questionamentos subjacentes giram em torno de: quais são as soluções multiculturais encontradas por eles? Quais são as respostas multiculturais que nossa família vai construir?

\section{Contato com a familia de origem}

O contato com a família de origem por intermédio de viagens ao país natal ou de visitas familiares ao país de acolhimento exerce papel importante no sentimento de pertencimento que integra a transmissão intergeracional. A relação com a família de origem dos pais permite aos filhos se reconhecer em uma configuração familiar em termos de: ordem de nascimento, de nome e de descendência, sem contar que essa representação familiar é extremamente importante na construção identitária e contribui ao processo de construção de um duplo pertencimento cultural. Outro elemento significativo é a relação estabelecida entre os filhos nascidos na terra de acolhimento e a família que ficou no país de origem, porque ajuda no processo de reencontro entre pais e filhos, significando compartilhamento da história familiar.

O espaço terapêutico pode ser o lugar em que, através da investigação e da tentativa de construção de um discurso familiar, esses aspectos podem ser abordados. Nesse sentido, é preciso detectar os pontos sensíveis, as zonas de so- 
frimento presentes na história familiar que podem provocar o sintoma (Daure \& Reveyrand-Coulon, 2012).

A terapia deve promover, em certa medida, uma "democratização da informação" com dois objetivos principais: o primeiro, ligado à comunicação, ou seja, a abrir as portas da memória familiar e a favorecer a circulação da história da família. O segundo, mais funcional, foca-se na tentativa de reconhecer as estratégias relacionais e pessoais utilizadas pelos membros do sistema durante o processo de adaptação, bem como nas modificaçóes do sistema provocadas pela imigração. $\mathrm{O}$ método de promoção da narração sobre a história da imigração ajuda o terapeuta na descoberta da família e na construção das hipóteses de trabalho que vão servir de guia na compreensão da dinâmica familiar e do sentido do sintoma. Essa abordagem de releitura da história familiar está presente de maneira mais ou menos marcante durante todo o processo terapêutico (Rosenbaum, 2009).

Nas famílias em que a história da imigração circula, nas quais um espaço criativo de interseção das duas culturas pode se exprimir, foi observada a melhor integração dos imigrantes e seus descendentes no país de acolhimento não só do ponto de vista social e laborativo, mas também da apropriação da cultura. Pudemos observar igualmente a importância de que alguns aspectos da história da imigração sejam abordados. Uma lista não exaustiva foi constituída, com o objetivo de servir de inspiração aos terapeutas ou aos profissionais de saúde que trabalham com população de imigrantes, porém, de modo algum, essa lista pode ser considerada completa e universal, uma vez que as particularidades das famílias e suas histórias devem ser certamente levadas em conta. Cada uma dessas perguntas pode ser feita para as pessoas que efetuaram a viagem imigratória, mas também para os seus descendentes, utilizando as expressóes: "O que você sabe sobre...?"; "Como você pensa que aconteceu...?"; "Do seu ponto de vista, como foi...?".

Com relação à viagem imigratória, o terapeuta deve se preocupar particularmente com as indagaçóes:

- De quem foi a ideia da imigração?

- Por que decidiram imigrar?

- Como era a vida no país de origem?

- Por que escolheram este país de acolhimento?

- Outras pessoas da família também imigraram? Quando? Onde?

- Para quem anunciaram o projeto imigratório? Por quê? Qual foi a reação?

- Segundo eles, quem foi a pessoa que mais sofreu com a imigração deles?

- Quem foi a pessoa que mais ajudou na realização do projeto? 
- Como vocês se organizaram para realizar a viagem?

- Quais eram as suas expectativas com relação ao país de imigração?

Com relação à viagem imigratória, o terapeuta deve estar atento aos seguintes aspectos:

- Na véspera da viagem, como se sentiram? Como era a atmosfera familiar?

- Quem os acompanhou até o lugar da partida?

- Como foi a viagem?

- Quais eram as ideias, os pensamentos que habitavam as cabeças deles durante a viagem?

Em termos da chegada ao país, dos primeiros contatos com a nova cultura e com os nativos, é importante saber, entre outros:

- Alguém estava esperando por eles?

- Tinham para onde ir?

- Como foram os primeiros contatos com a língua, os nativos, a cultura?

- Encontraram facilmente um trabalho?

- Mantiveram contato com a família de origem?

- Têm contatos com compatriotas no país de adoção?

- Preservaram ou tentaram preservar algumas tradiçóes culturais?

- De que modo as relaçóes entre eles e a família que ficou no país evoluíram?

- Quais as relaçóes entre os filhos e netos nascidos em país de imigração e a família que ficou no país de origem?

- A questão da imigração é abordada entre eles?

- Retornaram ao país de origem? Como se sentem quando estão lá?

- Como se sentem no país de acolhimento?

- Têm projeto de retorno ao país de origem?

Todas essas questóes, além das outras que derivam dessa investigação, irão servir para orientar a narração da odisseia migratória, possibilitando que o terapeuta perceba os recursos emocionais e relacionais da família, avalie a sua capacidade adaptativa e observe o lugar que tomam a cultura de origem e a cultura do país de acolhimento no cotidiano do sistema, assim como as zonas de intercessáo entre as duas culturas. O terapeuta deve adotar a postura de desconhecimento, uma atitude de curiosidade, a curiosidade do pesquisador, a do antropólogo, como descreve Andolfi (2004), mantendo o interesse com relação ao contexto 
relacional e afetivo conduzido pela disciplina e pela coerência terapêutica; caso contrário, o terapeuta corre o risco de se perder em consideraçóes exóticas, que nenhuma importância terapêutica representam.

Revisitar a história migratória com a ajuda do sistema familiar é o principal instrumento da Terapia Sistêmica Intercultural, que tem como objetivos:

- Revalorizar a cultura de origem da família.

- Revisitar as relaçóes entre o país de origem e a família que lá se encontra.

- Incentivar os membros da família a utilizar, sempre que possível, suas múltiplas bagagens culturais no cotidiano.

- Redinamizar as relaçóes intrafamiliares e extrafamiliares.

- Valorizar a diferença como referência identitária.

- Restituir a competência das famílias.

Conhecer os elementos da história da família imigrante e as referências culturais às quais pertence pode potencializar o processo, pois essa atitude terapêutica favorece as interaçóes no interior tanto do sistema familiar como do terapêutico. $\mathrm{O}$ caminho terapêutico de favorecimento da narrativa da história familiar e da história da imigração permite que os pais que efetuaram a viagem migratória se inscrevam em uma perspectiva de saber, de competência e de transmissão com relação aos seus filhos. Esse posicionamento reforça o papel dos pais, muitas vezes fragilizado pela falta de conhecimento dos elementos culturais e educativos da cultura do país de acolhimento. Essa dinâmica relacional favorece as interaçôes entre pais e filhos e inscreve mais facilmente os filhos de imigrantes em suas famílias de origem. O pertencimento a um grupo familiar é aspecto indispensável na construção identitária do sujeito. Assim, a inscrição familiar nos parece fator importante de estabilização do sujeito que, graças a esse sentimento de segurança, vai se interessar mais facilmente pela cultura do país de acolhimento. Nessa perspectiva, paradoxalmente, falar da cultura de origem, fazer viver o pertencimento familiar em termos de identidade cultural representa um potencial de integração importante.

\section{Discussáo}

Este trabalho foi construído no contexto francês, onde a questão da imigração ocupa lugar importante na esfera política, social e cultural; entretanto, algumas famílias em demanda de terapia que tivemos a oportunidade de en- 
contrar como psicóloga clínica e que viviam a experiência de migração, ou seja, viagem no interior de um mesmo país, apresentavam algumas das características que encontramos nos sistemas imigrantes aqui descritos. Essa observação nos autoriza a formular a hipótese de que reorganizaçóes relacionais ligadas ao deslocamento devem integrar a reflexão no âmbito da psicologia e da psiquiatria clínica.

A proposição do modelo de Terapia Sistêmica Intercultural aqui apresentado está em fase de aplicação, embora julguemos possível que surjam novas descobertas durante a sua utilização no tratamento de famílias imigrantes ou migrantes que conformem fontes de reflexão e de evolução da proposta Sistêmica Intercultural. Nossa experiência conduz a pensar que o trabalho de acolhimento das famílias de origem estrangeira deve favorecer o diálogo entre pais e filhos sobre a história da imigração e da família do país de origem. Essa perspectiva permite pensar o evento imigratório como gerador de crise intrapsíquica e intrafamiliar, que impóe ao sistema uma nova organização (Daure, 2011a).

Andolfi (2003) chama a nossa atenção para os aspectos ecológicos da vida familiar, tais como: o contexto social, os valores culturais, eventuais crenças religiosas e concernentes ao modo de vida, muitas vezes bastante diferentes entre a família e o psicólogo ou profissional de saúde encarregado do acompanhamento. Nesse sentido, observamos que o mais importante do ponto de vista terapêutico não é conhecer de antemão a cultura do outro, mas valorizar a sua competência cultural e abrir espaço para que elementos da cultura de origem do usuário/paciente possam ser abordados por ele e sua família. Uma atitude terapêutica baseada na curiosidade e no respeito à diferença cultural será, sem dúvida, uma valiosa ajuda na potencialização dos recursos da família e de maior fluidez nas relaçóes intra e extrafamiliares. O espaço terapêutico se torna uma autorizaçáo simbólica da circulação da história e das culturas.

Cavalieri (2004) aborda a curiosidade do psicólogo face ao imigrante com relação a três sentimentos que podem representar um obstáculo a esse movimento: o pudor, a humildade e o preconceito. $\mathrm{O}$ pudor estaria relacionado a certa reticência a perguntar, a compartilhar com a família outras zonas relacionais ou espaços de traumatismo ligados à imigração. A humildade implica uma postura de não saber, de ignorância; nesse caso, o psicólogo situa-se na posição de aprendizagem. Semelhante postura é nova e pode parecer arriscada ao especialista, uma vez que o preconceito impede o profissional de se interessar realmente pelo outro e se torna um elemento ambivalente, pois, ao mesmo tempo em que cega, guia o profissional em uma relação que ele pensa controlar. 
Falar da história da imigração é também uma maneira de compreender as modalidades interativas entre a família e a sociedade de acolhimento, os elementos que podem servir de suporte diagnóstico das eventuais dificuldades da família no contato cotidiano com o exterior, das possíveis tensóes entre a família e as instâncias representativas do país de acolhimento, como a escola, os serviços de saúde e, por fim, o nível de isolamento do sistema. No entanto, parece-nos extremamente importante explicar, neste ponto da análise, que nosso objetivo não é concentrar o terapêutico/a terapia em uma forma de culturalismo, o que seria táo nefasto quando o silêncio absoluto sobre as questóes de cultura. Trata-se aqui do espaço do "dizível”, do "pensável”, uma abertura, uma possibilidade que o sujeito pode alcançar com a ajuda do questionamento sobre as etapas da imigração e a história da família. Criar um espaço terapêutico onde o sujeito pode se apresentar em sua complexidade multicultural parece-nos essencial para a construção de um contexto que corresponda às necessidades do paciente e que náo dependa somente do universo psíquico e cultural do profissional. Nosso objetivo principal reside na ideia de criar um espaço de reflexão no âmbito da terapia familiar sistêmica sobre a particularidade do evento migratório na vida das famílias. De maneira alguma nossa ambição é a de categorizar, restringir e/ou determinar a maneira única de lidar com a questão do imigrante em terapia, pois, ao contrário, pensamos ser esse um modelo flexível e que representa uma abertura no sentido da compreensão e da valorização da diferença cultural. Tal deveria ser, em nosso modo de ver, a base do sentimento de reconhecimento e de acolhimento do outro, daquele que vem de uma cultura diferente.

A sensibilização dos profissionais de saúde mental para a questão da imigração facilita a definição do contexto de aparição do sintoma e a construção de uma experiência terapêutica mais próxima da realidade das famílias. O profissional trabalha no sentido de promover a melhor compreensão das contradições sociais e da diversidade cultural às quais são submetidos os imigrantes e seus descendentes, o que, do nosso ponto de vista, favorece a utilizaçáo positiva do duplo pertencimento e, como resultado, a melhor inscrição da família no país de adoção, sem que isso signifique perder de vista suas origens. A imigração pode ser vivida como riqueza ou perda, como vantagem ou fragilidade, ou tudo isso de acordo com as circunstâncias. As famílias que encontramos durante essa pesquisa são exemplos disso. Julgamos que é a equação entre o imigrante, seu país de origem, sua família de origem e o país de adoção que vai orientar a experiência imigratória como mais ou menos negativa ou positiva. Trata-se evidentemente de problemática com múltiplas variáveis, que vai ser influenciada por: idade, sexo, posição do sujeito na família de origem, nível de instrução, 
condição social, rede social de compatriotas e motivações da imigração. Além desses fatores, cada imigração é vivida de maneira singular por cada imigrante, pois dois membros da mesma família, que fizeram juntos o deslocamento imigratório, podem ter experiências imigratórias diversas quanto à tonalidade emocional. Tantos elementos constituem a história do sujeito e de sua identidade multicultural, que são capazes de influenciar várias geraçôes de descendentes se negligenciados, os quais, paralisados no tempo, podem apresentar dificuldades significativas de inscrição no país de acolhimento dos pais ou avós. A imigração é evento complexo que demanda adaptação não somente ao imigrante, mas também da sociedade de acolhimento através dos profissionais que a representam.

Para finalizar, algumas reflexóes sobre a realidade migratória no Brasil podem completar este artigo. $\mathrm{O}$ progresso, o desenvolvimento econômico e a passagem do país de terceiro mundo a país emergente, reconhecido como potência econômica em expansão, vão provocar necessariamente fortes impactos nas relaçôes entre o Brasil e outros países. Recentemente, a ocorrência de alguns processos migratórios, tais como a vinda de haitianos, nos fizeram refletir sobre o fato de que novas formas de imigração surgirão, uma imigração similar à que conhecem os países do velho continente, como a França. Uma imigraçáo em massa, nem sempre de forma legal, ou seja, imigração pela qual o deslocamento é o fruto da miséria na qual o imigrante se encontra no seu país de origem, onde imigrar se torna alternativa para sobreviver, pode trazer um conjunto de desafios a serem enfrentados. Muitas vezes o resultado da acumulação desses fatores é a imigração desorganizada não só do ponto de vista pragmático, mas também psíquico e emocional. As eventuais dificuldades encontradas pelo imigrante no país de acolhimento, a impossibilidade de o sujeito mobilizar suas capacidades adaptativas, pois já fragilizado pelo percurso imigratório, lançam-no, em alguns casos, em desespero profundo, o que dá origem a descompensaçóes psíquicas e a outras patologias do exílio.

Este artigo encontra toda a sua importância não só em contexto no qual as reflexôes e as teorizaçôes sobre as questôes da imigração e seu impacto sobre a população que sofre o deslocamento imigratório, mas também no âmbito do país de acolhimento, cujos efeitos devem ser rapidamente amortecidos. A imigração pode ser uma riqueza do ponto de vista individual, social e cultural. O Brasil é hoje um belo exemplo dessa competência criativa. Nessa perspectiva, as novas formas de imigração devem ser tratadas, pensadas e acolhidas de maneira a reforçar esse potencial produtivo, de valorização da competência cultural e do savoir faire do outro de cultura diferente. 


\section{Referências}

Andolfi, M. (2003). La mediazione culturale: tra l'estraneo e il familiare. Roma: Franco Angeli.

Andolfi, M. (2004). Famiglie immigrate e psiciterapia transculturale. Roma: Franco Angeli.

Ausloos, G. (2001). La compétence des familles: temps, chaos, processus. Ramonville Saint-Agne: Erès.

Cavalieri, L. (2004). Psicoterapia e immigrazione, due percorsi in una stanza. L'esperienza del servizio di consulenza psicologica alle famiglie sraniere di Roma. In: M. Andolfi (Ed.), Famiglie immigrate e psiciterapia transculturale (pp. 137-152). Roma: Franco Angeli.

Daure, I. (2006). Transmission le dilemme de la migration: un regard systémique. (Tese de Doutorado em Psicologia. Université Bordeaux-2. França).

Daure, I. (2010). Familles entre deux cultures: dynamiques relationnelles et prise en charge systémique. Paris: Fabert.

Daure, I. (2011). Approche Systémique Interculturelle: une proposition pour l'accueil des familles issues de la migration. Journal des psychologues, 290, 32-35.

Daure, I. (2011a). Transmettre pour une migration réussie. In Z. Guerraoui \& O. Reveyrand-Coulon (Eds.), Transmission familiale et Interculturelle: ruptures, aménagements, créations (pp. 43-58). Paris: In press.

Daure, I., \& Reveyrand-Coulon, O. (2012). Fratrie et exil: plasticité relationnelle et perspectives de soin. Dialogue Recherches sur le couple et la famille, 196, 25-36.

Friedman, E. J. (1994). Sensitivity to contextual variables: a legitimate learning objective for all supervisors? The supervision bulletin, $7(2), 102-115$.

Grinberg, L., \& Grinberg, R. (1986). Psychanalyse du migrant et de l'exilé. Lyon: Césura.

Guerraoui, Z. (2001). Situation interculturelle et dynamique identitaire. Les Cahiers de L'Actif, 250/251, 103-114.

Morrone, A., \& Mereu, F. (2003). La nuova realità dell'immigrazione: dal singolo alla famiglia. Dinamiche familiari e aspeti socio-sanitari. In M. Andolfi (Ed.), La mediazione culturale: tra l'estraneo e il familiare (pp. 73-100). Roma: Franco Angeli.

Mousset, S. (2011). La rencontre à l'épreuve de l'exil. Journal des psychologues, 290, 32-35.

Mugnier, J.-P. (1998). Les stratégies de l'indifférence. Paris: ESF.

Reveyrand-Coulon, O. (2011). Et si la langue parlait? Retour en langue et filiation. Journal des psychologues, 290, 28-31.

Rosenbaum, F. (2009). Les humiliations de l'exil: les pathologies de la honte chez les enfants migrants. Paris: Fabert.

Vasquez, A. (1993). Immigration et maternité. Toulouse: PUM. 


\section{Nota}

${ }^{1}$ Ivy Daure e Sabine Forzan exercem suas atividades profissionais como psicóloga e psiquiatra, respectivamente, no Hospital Psiquiátrico de Bordeaux, onde a consulta ambulatorial atende um número significativo de famílias imigrantes.

Recebido em 19 de maio de 2013 Aceito para publicaçáo em 10 de novembro de 2013 